\title{
Correction to: A two-stage Bayesian semiparametricmodel for novelty detection with robust prior information
}

\author{
Francesco Denti ${ }^{1}$ (1) $\cdot$ Andrea Cappozzo ${ }^{3}$ (D) $\cdot$ Francesca Greselin ${ }^{2}(1)$
}

Published online: 10 February 2022

○) Springer Science+Business Media, LLC, part of Springer Nature 2022

Correction to: Statistics and Computing (2021) 31:42

https://doi.org/10.1007/s11222-021-10017-7

Unfortunately, the original publication of the article contained the errors in typos, useless repetitions, and incorrect equations throughout the entire article. These errors have been corrected in the revised version.

The original article has been corrected.

Publisher's Note Springer Nature remains neutral with regard to jurisdictional claims in published maps and institutional affiliations.

The original article can be found online at https://doi.org/10.1007/ s11222-021-10017-7.

Francesco Denti fdenti@uci.edu

Andrea Cappozzo

andrea.cappozzo@polimi.it

Francesca Greselin

francesca.greselin@unimib.it

1 Department of Statistics and Computer Science, University of California Irvine, CA, USA

2 Department of Statistics and Quantitative Methods, University of Milano-Bicocca, Milan, Italy

3 MOX - Laboratory for Modeling and Scientific Computing, Department of Mathematics, Politecnico di Milano, Italy 